ORNL/TM-2007/169

\title{
PLASTIC STRAINING OF IRIDIUM ALLOY DOP-26 DURING CUP SIZING OPERATIONS
}

October 2007 
Materials Science and Technology Division

\title{
PLASTIC STRAINING OF IRIDIUM ALLOY DOP-26 DURING CUP SIZING OPERATIONS
}

\author{
E. K. Ohriner, A. S. Sabau, and G. B. Ulrich
}

Date Published: September 2007

\author{
Prepared by \\ OAK RIDGE NATIONAL LABORATORY \\ Oak Ridge, Tennessee 37831-6285 \\ managed by \\ UT-BATTELLE, LLC \\ for the \\ U.S. DEPARTMENT OF ENERGY \\ Under contract DE-AC05-00OR22725
}




\section{TABLE OF CONTENTS}

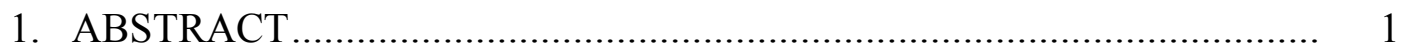

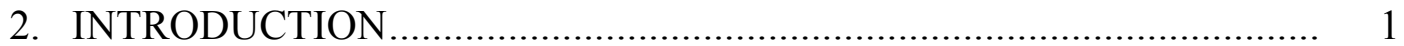

3. MATERIALS AND PROCEDURES........................................................ 3

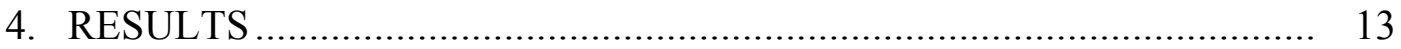

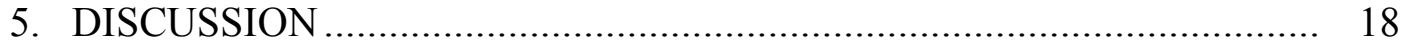

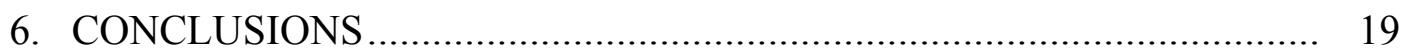

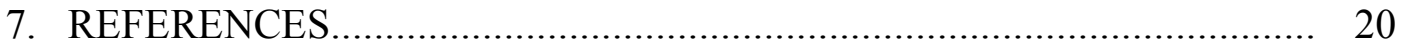




\section{LIST OF FIGURES}

Figure 1. Iridium DOP-26 alloy deep drawn cup.

Figure 2. Roundness plot of outer contour of deep drawn cup 4359 has maximum depression depth of $0.05 \mathrm{~mm}$

Figure 3. Roundness plot of outer contour of deep drawn cup 5363 shows maximum depression depth of $0.07 \mathrm{~mm}$

Figure 4. Second roundness plot of deep drawn cup 5363 with both inner and outer contours shows no change in wall thickness in the regions of depressions

Figure 5. Roundness plot of outer contour of cup 4359 after sizing shows maximum depression depth of $0.028 \mathrm{~mm}$

Figure 6. Roundness plot of outer contour of cup 5363 after sizing shows maximum depression depth of $0.035 \mathrm{~mm}$

Figure 7. True Stress - True Strain Data for Iridium Alloy DOP-26 at $20^{\circ} \mathrm{C}$

Figure 8. Overall geometric input for modeling of cup 4359 with variations in input labeled as $\mathrm{d} 1$ and $\mathrm{d} 2$ to accommodate die clearances of $0.03 \mathrm{~mm}$ and $0.05 \mathrm{~mm}$

Figure 9. Overall geometric input for modeling of cup 5363

Figure 10. Geometric input detail for modeling of cup 5363 shows one half of a symmetrical groove in the cup.

Figure 11. Calculated equivalent plastic strain for cup 4359 for case a) $0.03 \mathrm{~mm}$ radial die clearance at $55 \mathrm{kN}$ load and b) $0.03 \mathrm{~mm}$ radial die clearance at $90 \mathrm{kN}$ load.

Figure 12. Calculated equivalent plastic strain for cup 5363 with $0.05 \mathrm{~mm}$ radial die clearance for case a) $55 \mathrm{kN}$ load and b) $90 \mathrm{kN}$ load.

Figure 13. Calculated equivalent plastic strain for simulation of $0.67-\mathrm{mm}$ thick sheet bent 90 degrees over a rigid cylindrical bar of $12.7 \mathrm{~mm}$ radius 


\section{ABSTRACT}

DOP-26 iridium alloy cups are used for fuel cladding for radioisotope power systems. The cups are deep drawn and recrystallized prior to final fabrication operations. This study characterizes the plastic deformation of cups during a sizing operation following the recrystallization heat treatment. The purpose of the sizing operation is to achieve the specified roundness, diameter, and radius dimensions of the cup. The operation introduces various levels of plastic strain in the cup. Plastic strain can be a cause of inhomogeneous or abnormal grain growth during subsequent exposure to elevated temperature during the service life of the fuel cladding. This is particularly true in the case of cups which have irregularities in the cup walls from the deep drawing operations. Diameter and roundness measurements were made on two cups both before and after sizing. Plastic strain levels were calculated using the ABAQUS ${ }^{\mathrm{TM}}$ finite element software. The calculated plastic strain levels in both cups were below 0.025 , a value shown to be below the critical strain for abnormal grain growth during a simulated service exposure. The calculated maximum plastic strain was found to increase with increased applied sizing load and was not sensitive to the input value for the clearance between the cup and the sizing die. The calculated geometry of the sized cups was in good agreement with the measurements on the finished cups.

\section{INTRODUCTION}

Iridium alloy cups are used for fuel containment in radioisotope power systems. A typical cup is shown in Figure 1. The DOP-26 iridium alloy (Ir- $0.3 \% \mathrm{~W}-0.006 \% \mathrm{Th}-$ $0.005 \% \mathrm{Al}$, by weight) provides the desired mechanical properties, oxidation and corrosion resistance, and chemical compatibility with the fuel and carbon insulation materials. The mechanical properties, and in particular the tensile ductility at high strain rates, are effected by the grain size of the alloy. The cups are formed by deep drawing (in two drawing operations) of stress-relieved iridium alloy blanks at $925^{\circ} \mathrm{C}$ using punches and dies preheated to $250^{\circ} \mathrm{C}$. The cups are cleaned and recrystallized at $1375^{\circ} \mathrm{C}$ followed by cold sizing in a closed steel die. Sizing pressure is applied through a polyurethane punch to obtain the specified cup diameter, radius, and roundness dimensions. Plastic strains are introduced into the cup during the sizing operation, the values of which depend on the details of the initial cup geometry. Under normal conditions the plastic strains are less than $1 \%$ and are of no concern. However, on infrequent occasions buildup of dried and hardened lubricant material on the second-forming die can result in local depressions or grooves in the outer contour of the cup wall and concomitant bulges on the inner contour. The subsequent sizing operation can decrease the extent of these impressions with a consequential introduction of a local plastic strain in that region. This strain is a potential source of abnormal grain growth. 


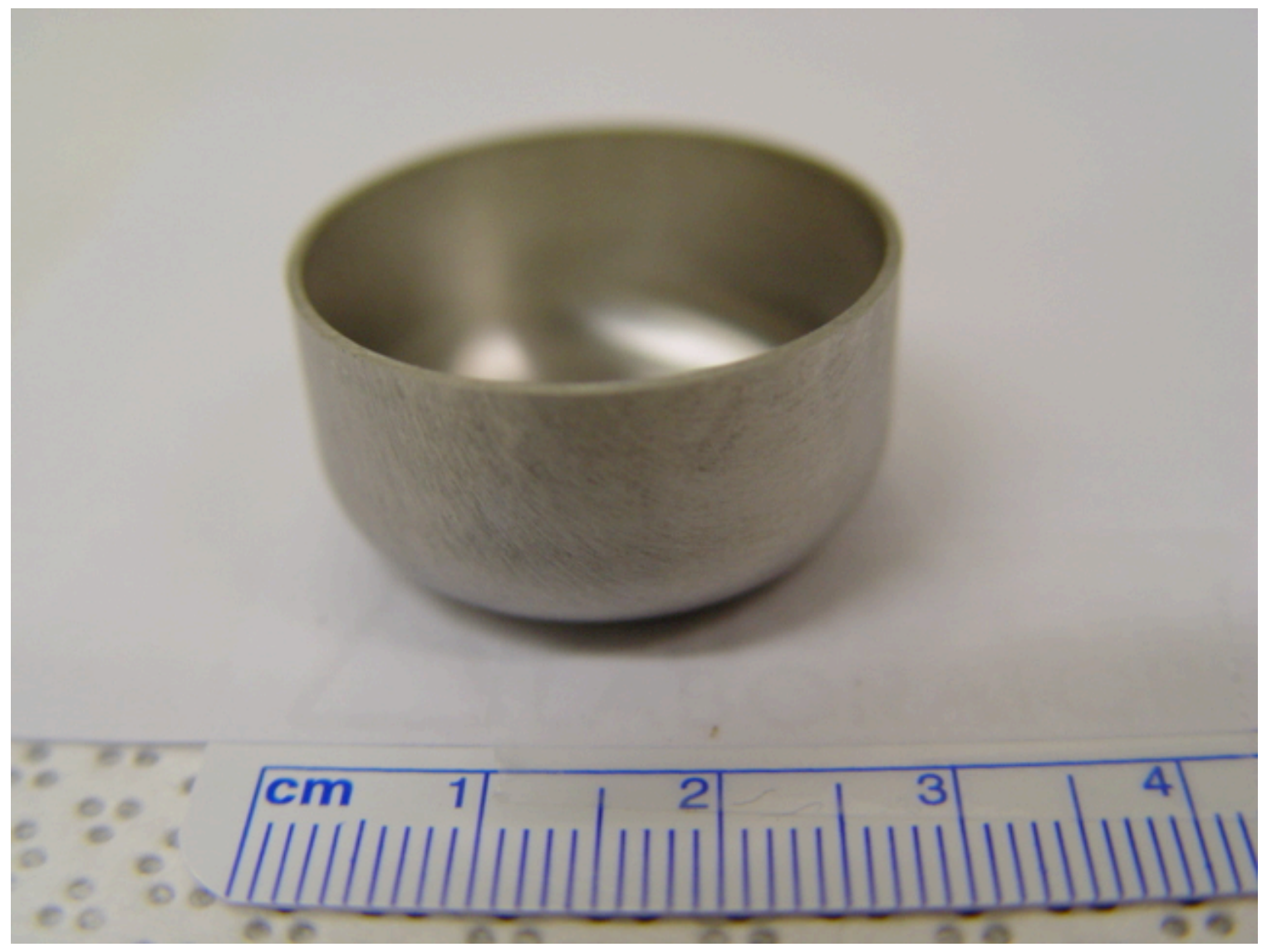

Figure 1. Iridium DOP-26 alloy deep drawn cup.

It has been shown for iridium [1] as well as other metals and alloys [2,3] that plastic strains in the range of 2 to $10 \%$ can result in abnormal grain growth during subsequent heating at elevated temperature. Abnormal grain growth is non-uniform grain growth in which a few grains grow rapidly while the majority of grains in the structure exhibit little or no growth. The nature of the grain growth and its dependence on prior plastic strain depends on the material composition, initial grain size, texture effects, and the subsequent time-temperature profile. Generally some distribution of second phase particles is present to inhibit normal grain growth. There is an incubation time for abnormal grain growth which decreases with increased temperature and prior plastic strain level. The final grain size is greatest for an intermediate level of plastic strain - about $5 \%$ for iron. [2]

In the case of the DOP-26 iridium alloy [1] it was shown that it was possible to induce abnormal grain growth in formed cups containing localized impressions from hardened lubricant on the forming die that were subsequently recrystallized, sized, and then heated for 100 hours at $1500^{\circ} \mathrm{C}$. The study also showed that plastic bending strains as low as $1.3 \%$ at the specimen surface could initiate abnormal grain growth at $1500 \mathrm{C}$. The material, in actual service, would not be exposed to temperatures above $1330 \mathrm{C}$ for extended periods of more than one hour. Exposures of 3 months at $1330 \mathrm{C}$ showed 
minimal evidence of abnormal grain growth for material with $2.5 \%$ strain in bending. For sheet material with 5\% strain in bending a region of abnormal grain growth extended about one quarter of the material thickness from both the inner and outer surfaces.

The purpose of this study was to evaluate the use of finite element analysis to determine plastic strain distributions in two selected iridium alloy cups following sizing operations. The strain distribution in bend specimens was also modeled to provide a direct comparison to the earlier study of abnormal grain growth.

\section{MATERIALS AND PROCEDURES}

Nine of 24 cups from a single lot were formed with noticeable depressions in the outer cup wall resulting from lubricant build-up on the second-forming die. The outer contours of all of the cups were characterized using a Formscan 3200 Circular Geometry Gage (Federal Products Co. Providence, RI - currently Mahr Federal Inc.) in the least squares circle (LSC) mode. The measuring stylus had a teardrop shape with both maximum width and diameter of $1.6 \mathrm{~mm}(0.062 \mathrm{in})$ and length of $4.1 \mathrm{~mm}(0.160 \mathrm{in})$. Measurements were made using the $1.6 \mathrm{~mm}$-wide face - not the sharp tip of the teardrop. Plots of the deviation of the outer contour of the cup from roundness using the least squares circle method, or roundness plots, were evaluated at heights of $8.8,11.4$, and 14.1 $\mathrm{mm}$ from the bottom of each cup. Roundness was measured as the difference between the maximum and minimum deviations from the least squares circle. The depression depths were measured as the local minimum negative deviation from the least squares circle. The cups with forming lubricant depressions were found to have maximum out-ofroundnesses and depression depths at the $8.8 \mathrm{~mm}$ height. Cups without forming lubricant depressions were found to have maximum out-of-roundnesses and depression depths at the $14.1 \mathrm{~mm}$ height.

The two cups analyzed in this study, identified by their serial numbers 4359 and 5363 , were selected from the group of nine cups formed with noticeable depressions, as representative of cups with the respective smallest and largest depression depths. Roundness plots of the outer contour for these cups are shown in Figures 1 and 2. The maximum depression depths for cups 4359 and 5363 are 0.05 and $0.07 \mathrm{~mm}$, respectively. Inside and outside diameter measurements were made at the $8.8 \mathrm{~mm}$ latitude for these cups using a Cordax 1820 (Sheffield Measurement, a division of Hexagon Metrology, Inc. Fond du Lac, WI) coordinate measuring machine with a Renishaw (Gloucestershire, UK) PH9/Mk2 probe head and TP2 ruby tip ( $2 \mathrm{~mm}$ ball diameter). Surface contour measurements of both the inside and outside of the cups with forming lubricant depressions made at the $8.8 \mathrm{~mm}$ heights confirmed that depressions on the outside coincided with protrusions on the inside. Figure 3 is a representative concentricity plot showing this for cup 5363. Although the origins of inner and outer contours are offset, it is clear that the contour deviations are not associated with significant variations in wall

thickness. The dimensional characteristics of cups 4359 and 5363 at their $8.8 \mathrm{~mm}$ heights 
are summarized in Table 1. All of these data were the basis for the modeling described below.

After the pre-sizing contour measurements were completed, the cups were cleaned, recrystallized in vacuum at $1375^{\circ} \mathrm{C}$ for 1 hour, and then sized in a closed steel die of $29.749 \mathrm{~mm}$ inside diameter with a roundness of $0.006 \mathrm{~mm}$ at the $8.8 \mathrm{~mm}$ height from the die bottom. Sizing was performed on a Wabash (Wabash, IN) 30 ton hydraulic press using a polyurethane punch with an applied load on the order of $55 \mathrm{kN}(12000 \mathrm{lb})$. The measurements of roundness of the outer contour and diameter were repeated. The measured outer contours at the $8.8 \mathrm{~mm}$ height are shown in Figures 4 and 5 . The cup dimensions following sizing are also listed in Table 1.

Numerical simulations of the dimensional changes in the cylindrical portion of closed-bottom deep drawn iridium cups were performed in a static analysis conducted using a two-dimensional finite element model for mechanical analysis developed within the commercial software ABAQUS ${ }^{\mathrm{TM}}$. It was assumed that the polyurethane punch used for sizing was in a state of hydrostatic compression equivalent to the applied load divided by the cross sectional area of the $28.3 \mathrm{~mm}$ inner diameter of the cup. Two levels of applied load, $55 \mathrm{kN}(12,000 \mathrm{lb})$ and $90 \mathrm{kN}(20,000 \mathrm{lb})$, nominally equivalent to pressures of $85 \mathrm{MPa}$ and $145 \mathrm{MPa}$ respectively, were modeled for each of the two cups in order to evaluate the effect of this parameter. The lower of these two loads is the approximate load applied to the cups during sizing. The larger load value is estimated to be the highest load that might be applied during cup sizing with the existing equipment. In the case of cup 4359, a mean clearance to the sizing die of $0.05 \mathrm{~mm}$ was modeled in addition to the measured value of $0.03 \mathrm{~mm}$ to determine the sensitivity of sizing strain to this parameter.

\section{Table 1. Dimensional Characteristics of Cups After Forming and After Sizing}

\begin{tabular}{lcc}
\hline Measurement*, mm & No. 4359 & No. 5363 \\
\hline & \multicolumn{2}{c}{ Formed Cup } \\
\cline { 2 - 3 } Cup maximum depression depth & 00.050 & 00.070 \\
Cup roundness, inside & 00.097 & 00.120 \\
Cup roundness, outside & 00.098 & 00.133 \\
Cup wall thickness & 00.685 & 00.658 \\
Cup outer diameter & 29.686 & 29.650 \\
Cup radial die clearance & 00.032 & 00.050 \\
& \multicolumn{2}{c}{ Sized Cup } \\
Cup maximum depression depth & 00.028 & 00.035 \\
Cup roundness, outside & 00.034 & 00.042 \\
Cup outer diameter & 29.754 & 29.759 \\
\hline
\end{tabular}

*All cup measurements at cup height of $8.8 \mathrm{~mm}$ 


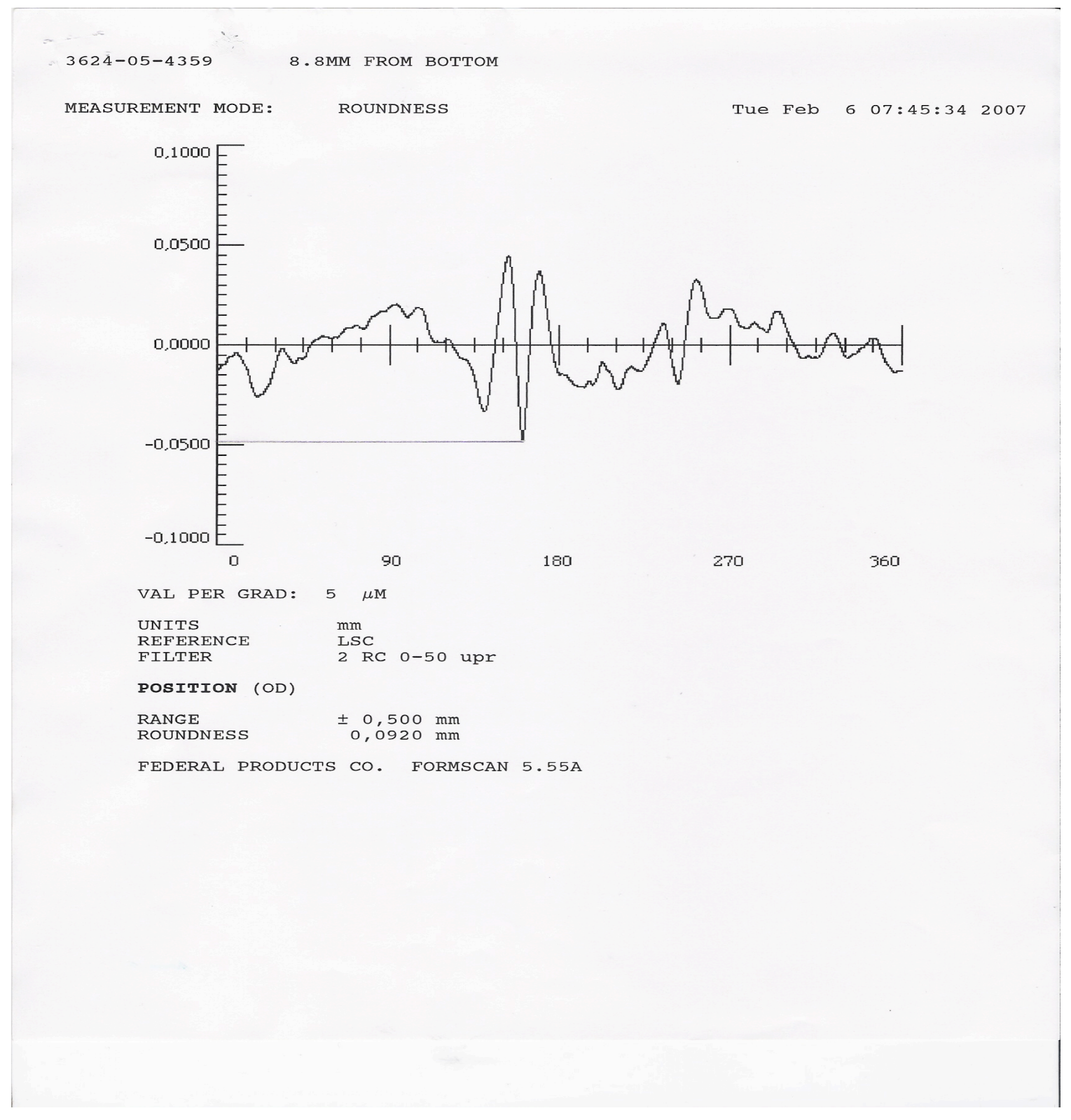

Figure 2. Roundness plot of outer contour of deep drawn cup 4359 has maximum depression depth of $0.05 \mathrm{~mm}$. 


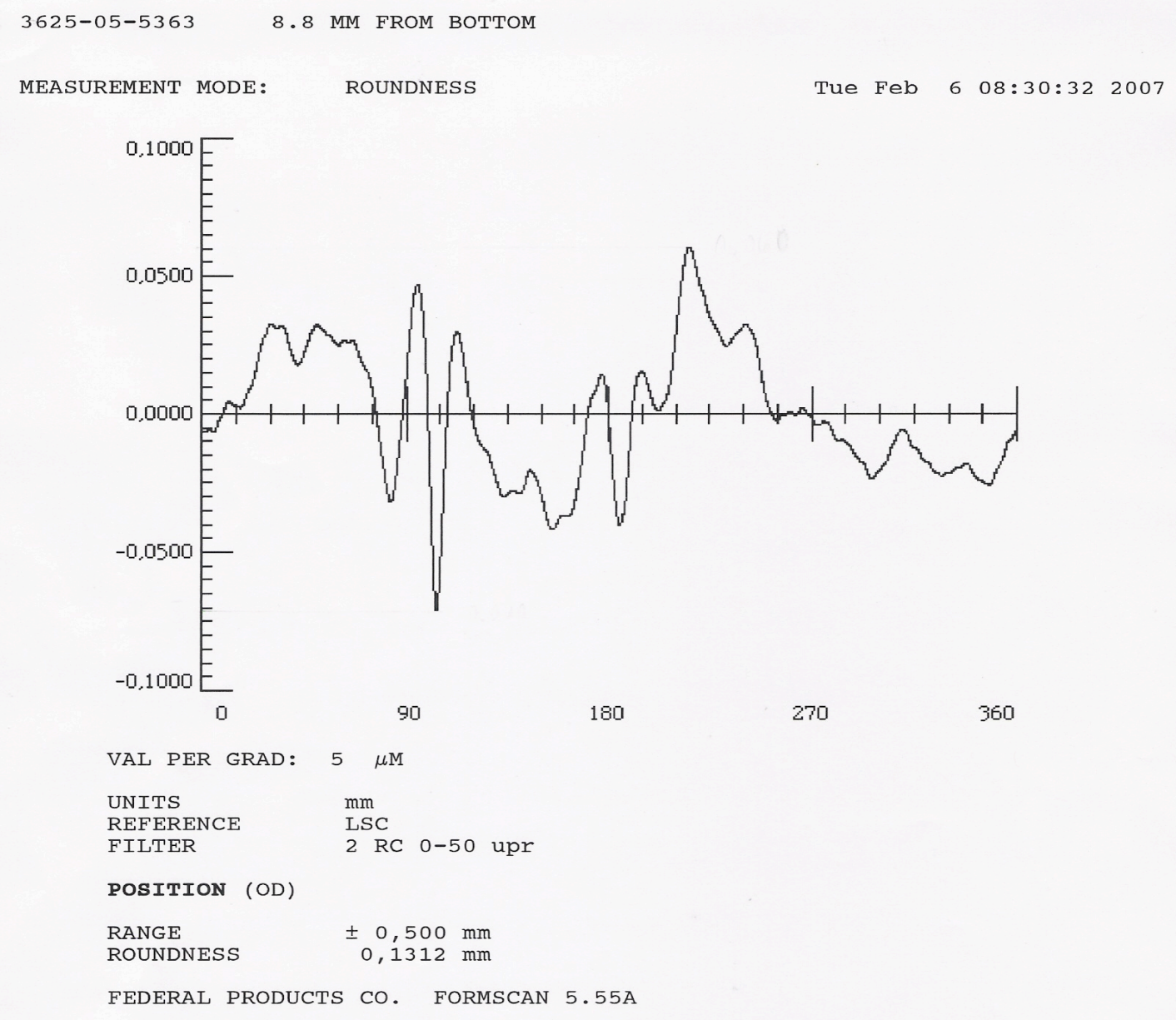

Figure 3. Roundness plot of outer contour of deep drawn cup 5363 shows maximum depression depth of $0.07 \mathrm{~mm}$. 


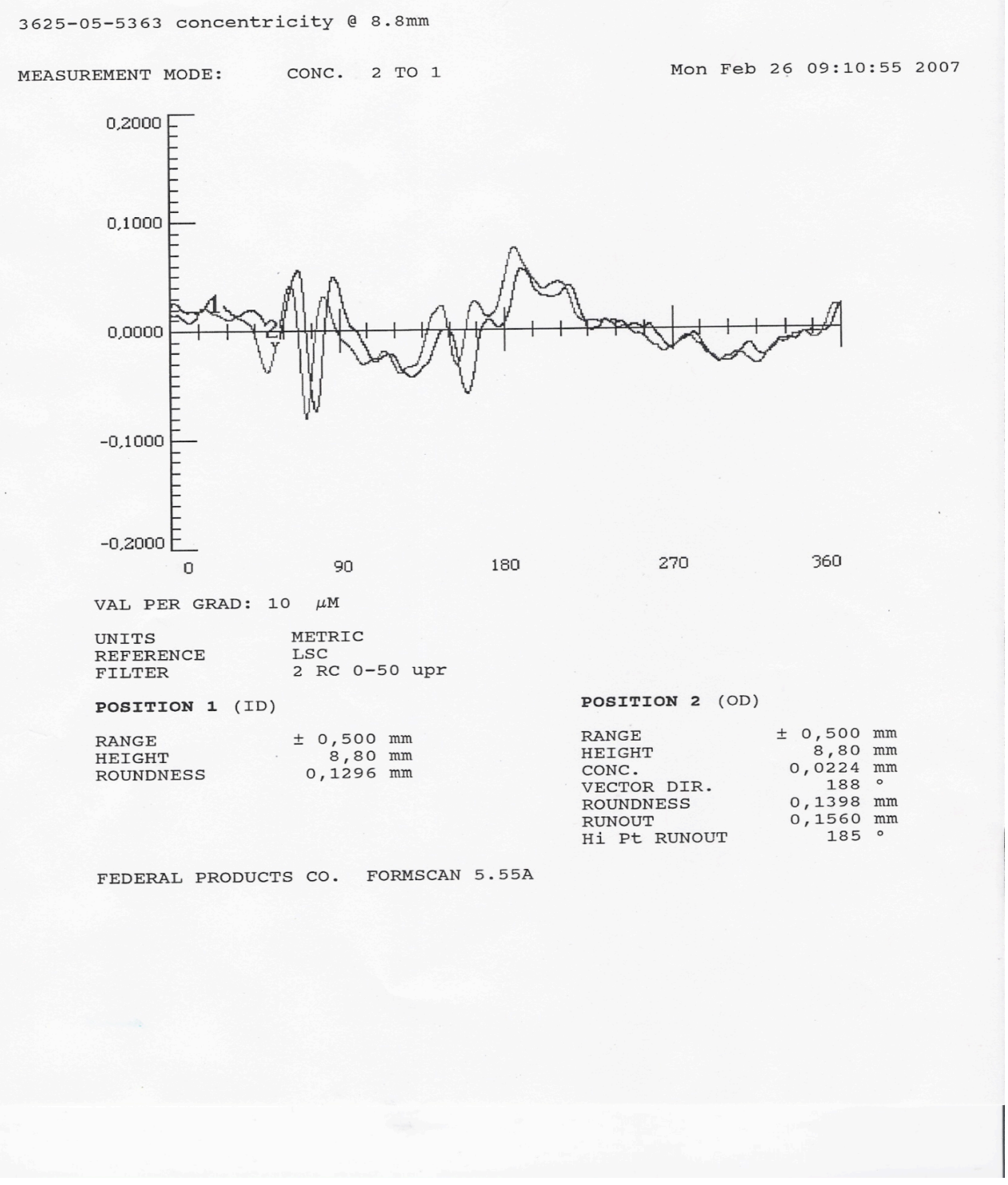

Figure 4. Second roundness plot of deep drawn cup 5363, with both inner and outer contours, shows no change in wall thickness in the regions of depressions. 
$3624-05-4359$ OD

MEASUREMENT MODE: ROUNDNESS

Mon Mar 5 10:43:43 2007

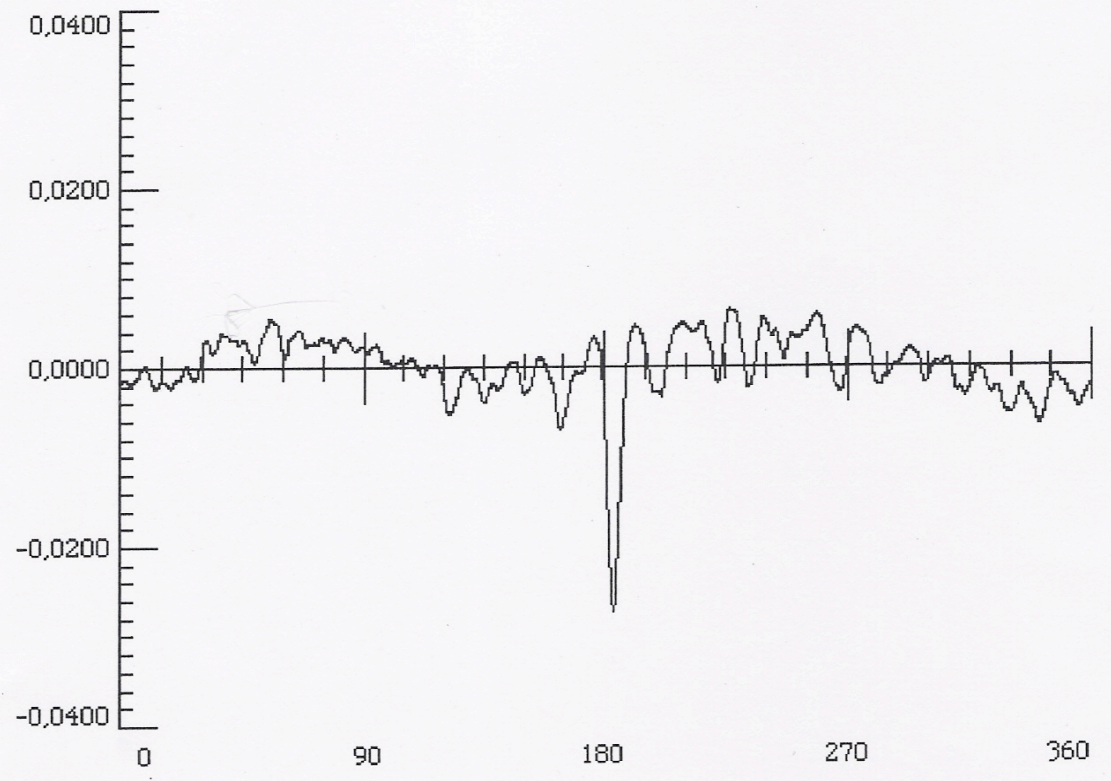

VAL PER GRAD: $2 \mu \mathrm{M}$

UNITS $\mathrm{mm}$

REFERENCE ISC

FILTER 2 RC $0-50$ upr

POSITION (OD)

$\begin{array}{lr}\text { RANGE } & \pm 0,500 \mathrm{~mm} \\ \text { ROUNDNESS } & 0,0336 \mathrm{~mm}\end{array}$

FEDERAL PRODUCTS CO. FORMSCAN $5.55 \mathrm{~A}$

Figure 5. Roundness plot of outer contour of cup 4359 after sizing shows maximum depression depth of $0.028 \mathrm{~mm}$. 


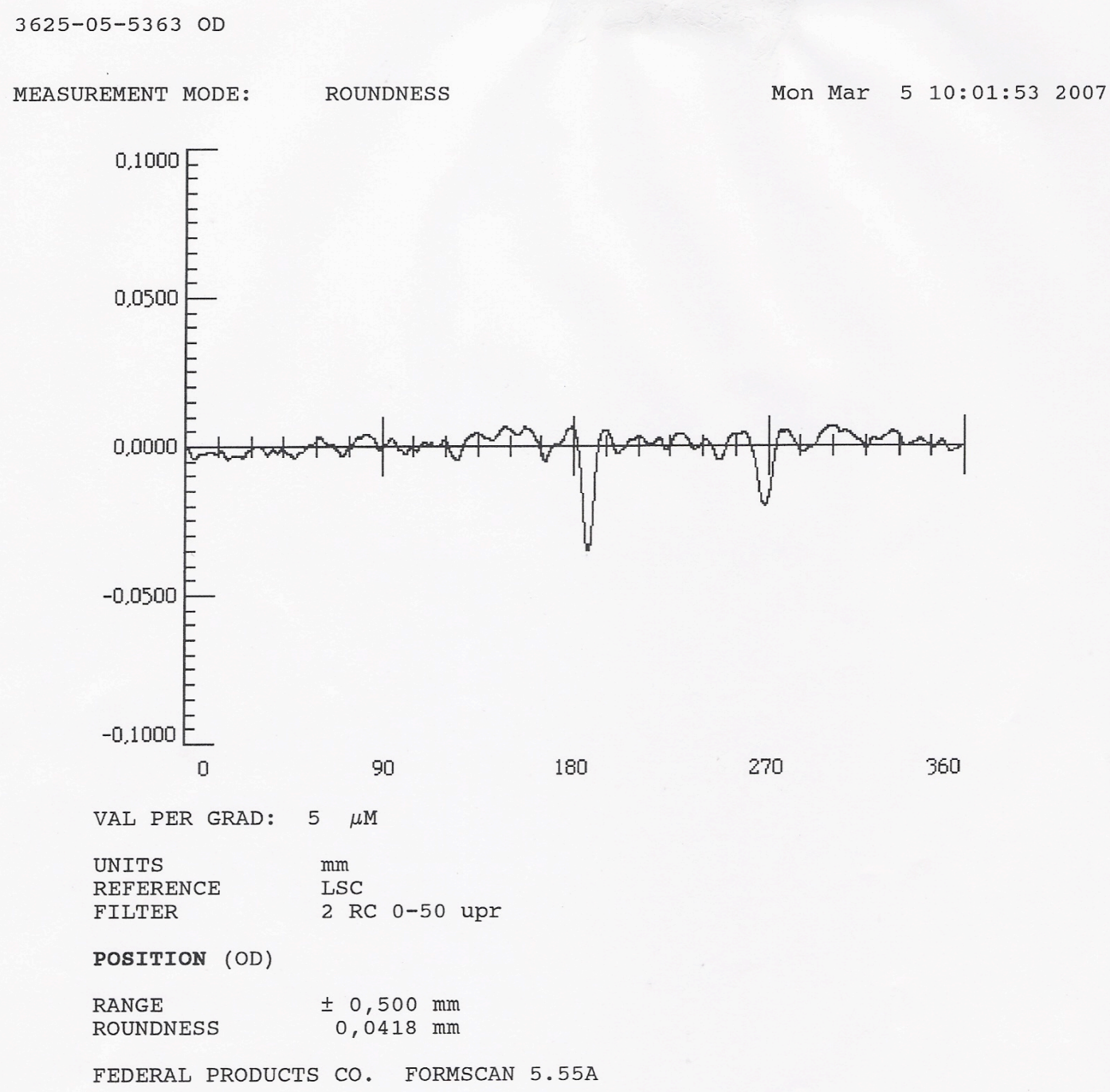

FEDERAL PRODUCTS CO. FORMSCAN 5.55A

Figure 6. Roundness plot of outer contour of cup 5363 after sizing shows maximum depression depth of $0.035 \mathrm{~mm}$. 
Input data for the model consisted of tensile stress strain data, elastic modulus, and cup and die geometry. Mechanical property data was obtained from room temperature tensile test data for recrystallized DOP-26 alloy at a strain of $10^{-3} \mathrm{~s}^{-1}[4]$. The tensile true stress - true strain data are shown in Fig. 6. The elastic modulus of pure iridium of 528 $\mathrm{GPa}$ was used [5]. The output consisted of calculated dimensions, displacements, and strain. The strain was calculated as an equivalent plastic strain, $\varepsilon_{e q}^{p}$, which is determined by integration over time from the equivalent strain rate, $\dot{\varepsilon}_{e q}^{p}$, expressed as:

$$
\varepsilon_{e q}^{p}=\int_{0}^{t} \dot{\varepsilon}_{e q}^{p} d t ;
$$

in which

$$
\dot{\varepsilon}_{e q}^{p}=\sqrt{\frac{2}{3} \sum_{i j} \dot{\varepsilon}_{i j}^{p} \dot{\varepsilon}_{i j}^{p}} .
$$

The pressure was increased in several steps to insure good convergence properties in the numerical simulations of the sizing operation. The simulations were conducted in the static mode and the die walls were considered to be rigid. After the loading step was complete, the unloading step was considered, including the relaxation of the elastic strains. The initial cup geometry for the deformation model was simplified to include only those features in the region of the deepest depression in each cup. The cup was considered to be symmetrical with respect to the axis of the depression. In the case of cup 4359 a protrusion on the cup surface in the vicinity of the depression was included in the input geometry for the case of die clearance of $0.05 \mathrm{~mm}$, but was truncated in the input for the case of the $0.03-\mathrm{mm}$ die clearance to avoid a geometric interference. (The geometric measurements indicated that the cup would not fit in the sizing die without some elastic deformation, which was not treated in this analysis.) The two variations in the input geometry for cup 4359 are shown in Figure 7. The overall input geometry for cup 5363 is shown in a polar plot in Figure 8. The details of the measured geometry of the depression used in the model are shown in Figure 9. 


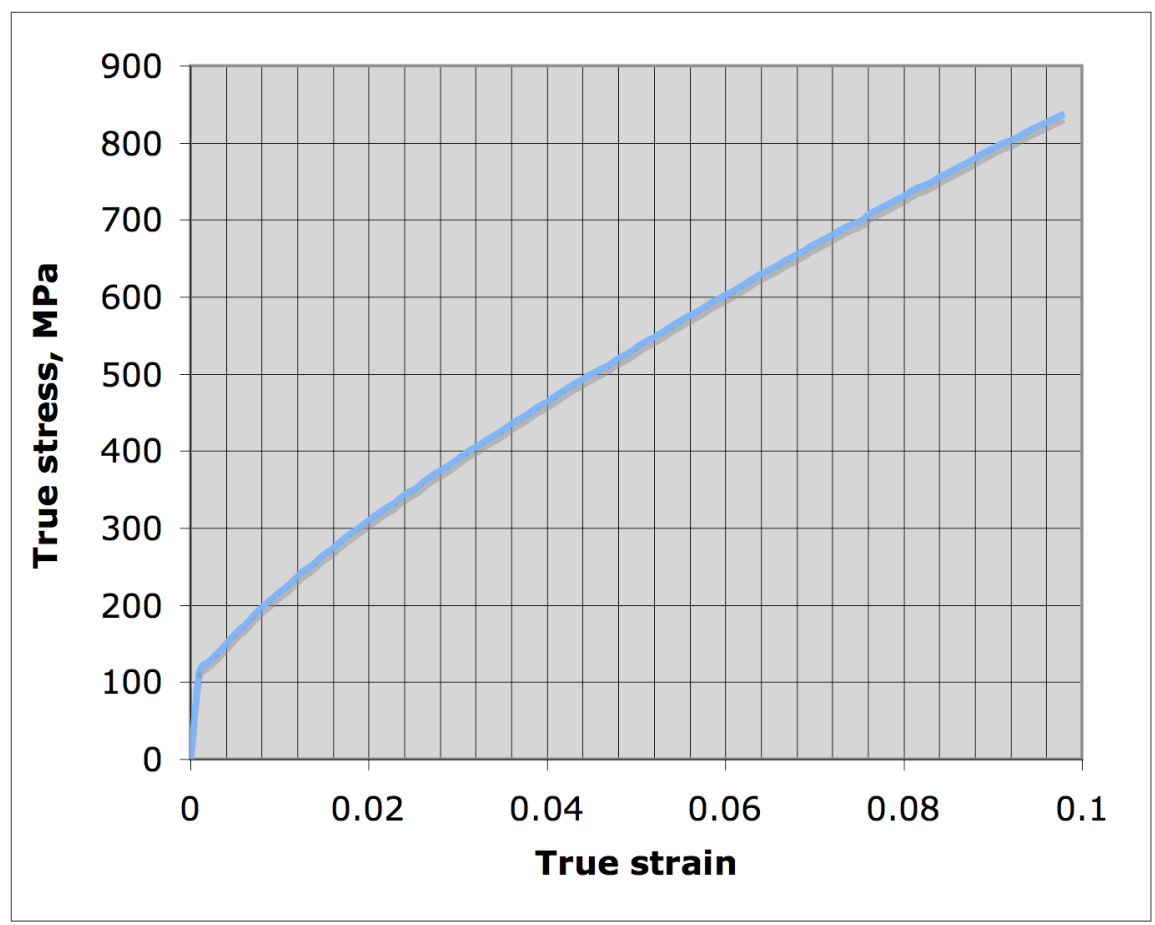

Figure 7. True Stress - True Strain Data for DOP-26 Iridium Alloy at 20 C, from reference 4 .

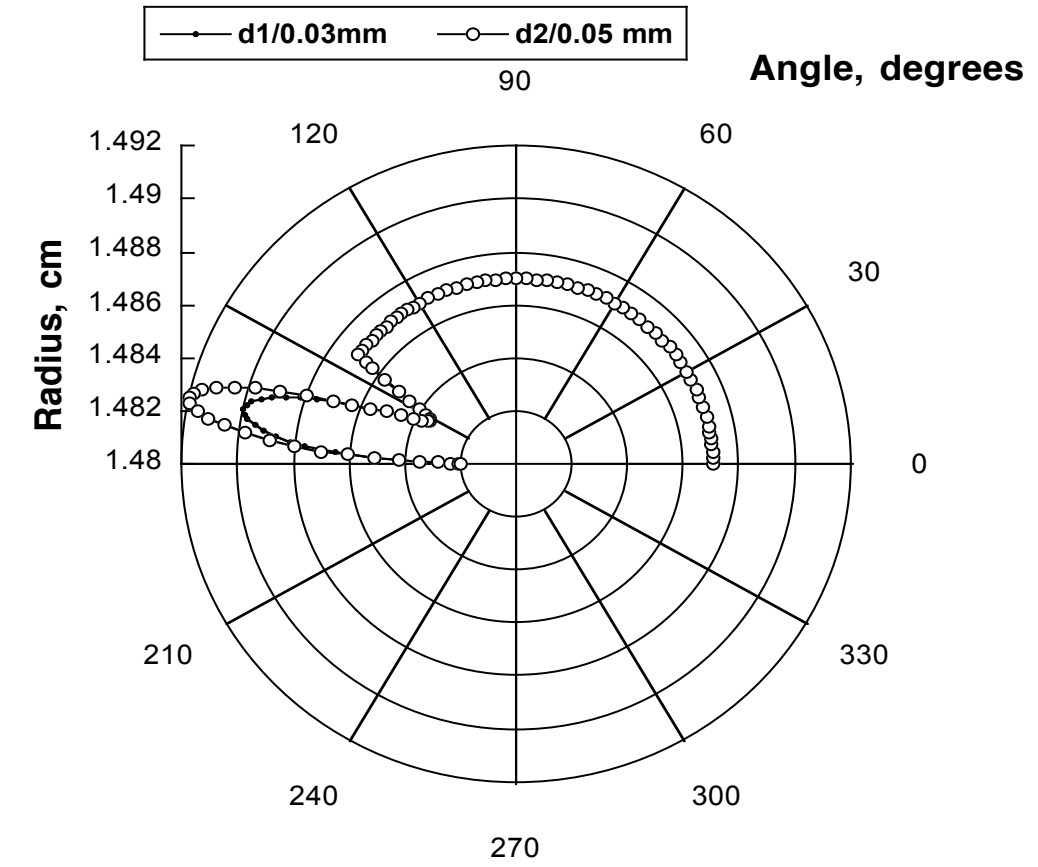

Figure 8. Overall geometric input for modeling of cup 4359 with variations in input labeled as $\mathrm{d} 1$ and $\mathrm{d} 2$ to accommodate die clearances of $0.03 \mathrm{~mm}$ and 0.05 $\mathrm{mm}$. The cup radius was assumed to be symmetrical about the centerline of the depression located at $180^{\circ}$. 


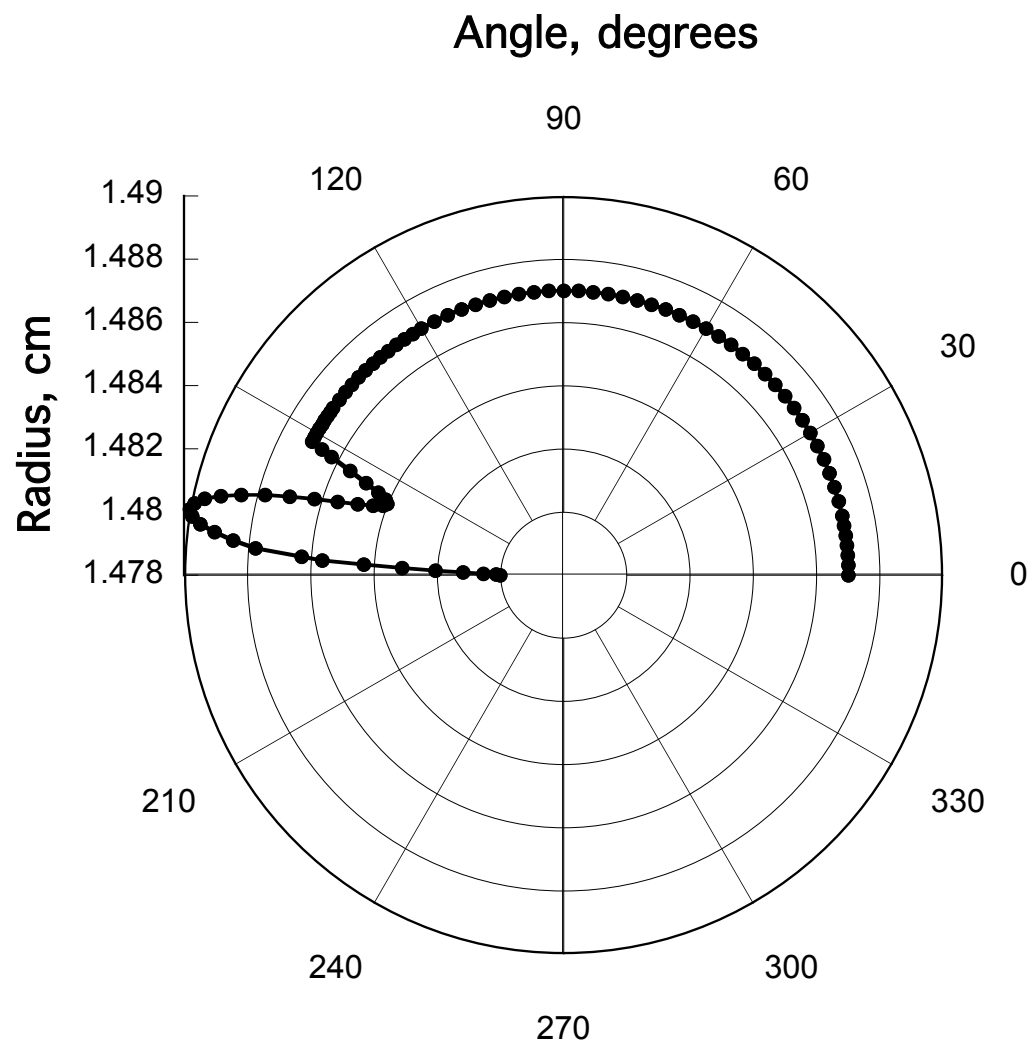

Figure 9. Overall geometric input for modeling of cup 5363. The cup radius was assumed to be symmetrical about the centerline of the depression located at $180^{\circ}$.

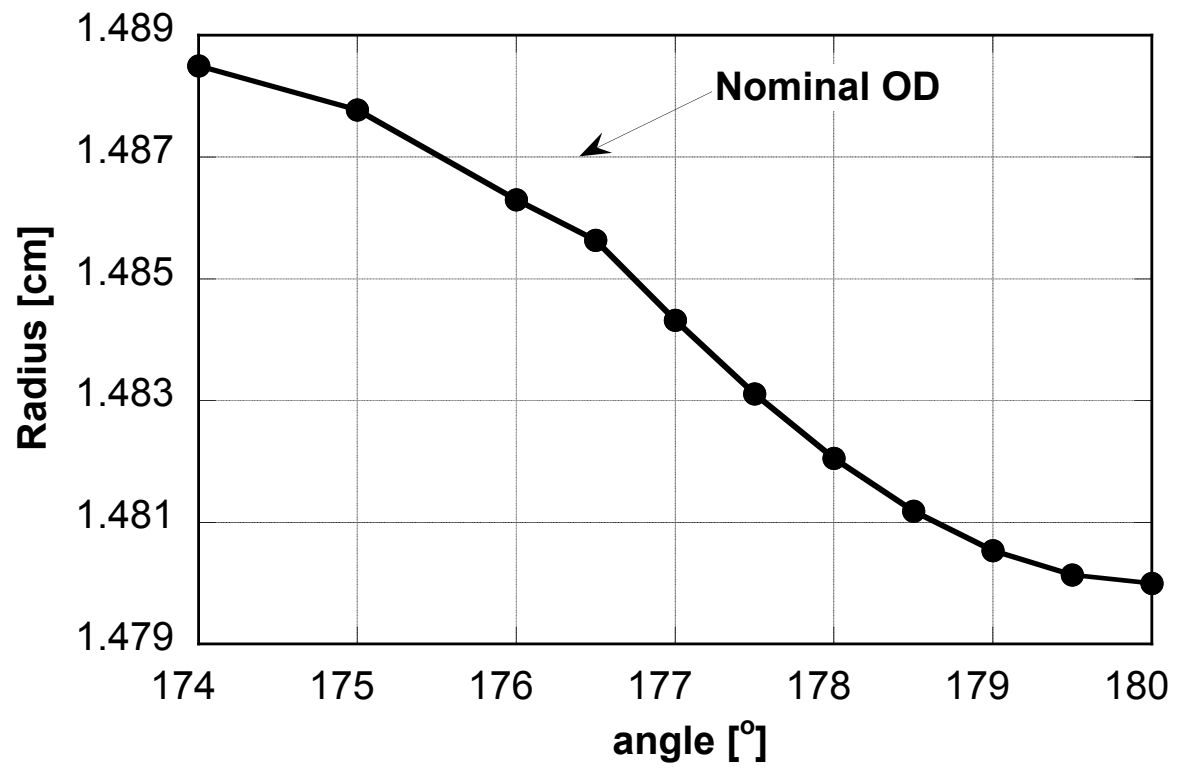

Figure 10. Geometric input detail for modeling of cup 5363 showing one half of a symmetrical groove in the cup. 
Numerical simulations of bending of iridium alloy sheet material of $0.67-\mathrm{mm}$ thickness were also performed with the commercial software ABAQUS ${ }^{\mathrm{TM}}$ for the purpose of verifying plastic strain calculations in earlier reports. In a previous study [1] bend samples were given long-term exposure at elevated temperature to determine grain growth behavior of strained material. Bends of 90 degrees were made over steel mandrels of various sizes. Plastic strains were estimated using the standard formula for calculation of maximum fiber strain:

$$
\begin{aligned}
& \varepsilon_{\text {eng }}^{p}=t / 2 r \\
& \varepsilon_{\text {true }}^{p}=\ln \left(\varepsilon_{\text {eng }}^{p}\right)
\end{aligned}
$$

in which

$\mathrm{t} \quad$ is the sheet thickness

$\mathrm{r} \quad$ is the radius of the bend

$\boldsymbol{\varepsilon}_{\text {eng }}^{p}$ is the maximum value of the fiber strain measured as engineering plastic strain and

$\boldsymbol{\varepsilon}_{\text {true }}^{p}$ is the maximum value of the fiber strain measured as true plastic strain.

In the current model of three point bending the supports were considered rigid and the bend samples of $25 \mathrm{~mm}$ length were considered to deform under an increasing load until a bend of about 90 degrees was obtained.

\section{RESULTS}

The equivalent plastic strains calculated for cup 4359 are shown in Figure 10 for two conditions of applied load and two conditions of die clearance during sizing. In all four cases the maximum equivalent plastic strain is located about 6 degrees from the centerline of the depression, near the start of the depression. The maximum strain is typically located either at the outer surface of the cup or just beneath it. The maximum value of the equivalent plastic strain for each of the four conditions is summarized in Table 2. The maximum strain is affected by the applied load. It is about $2 \%$ for a sizing load of $55 \mathrm{kN}$ and about $3 \%$ for a sizing load of $90 \mathrm{kN}$. The maximum strain is insensitive to normal variations in die clearance. The equivalent plastic strains calculated for cup 5363 are shown in Figure 11 for the same two conditions of applied load $-55 \mathrm{kN}$ and $90 \mathrm{kN}$. The maximum strain locations and values are similar to those for cup 4359 as shown in Table 2. 


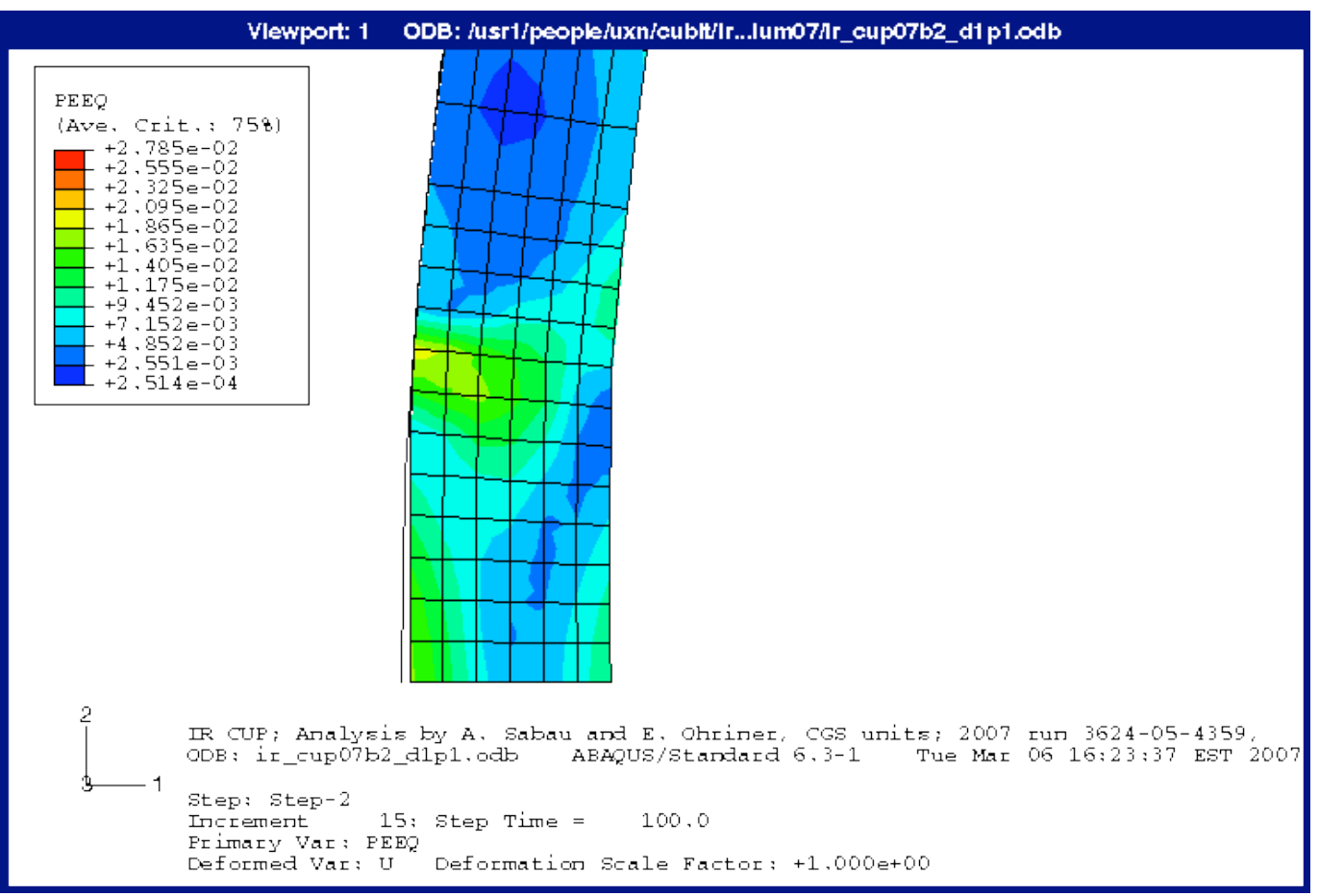

(a)

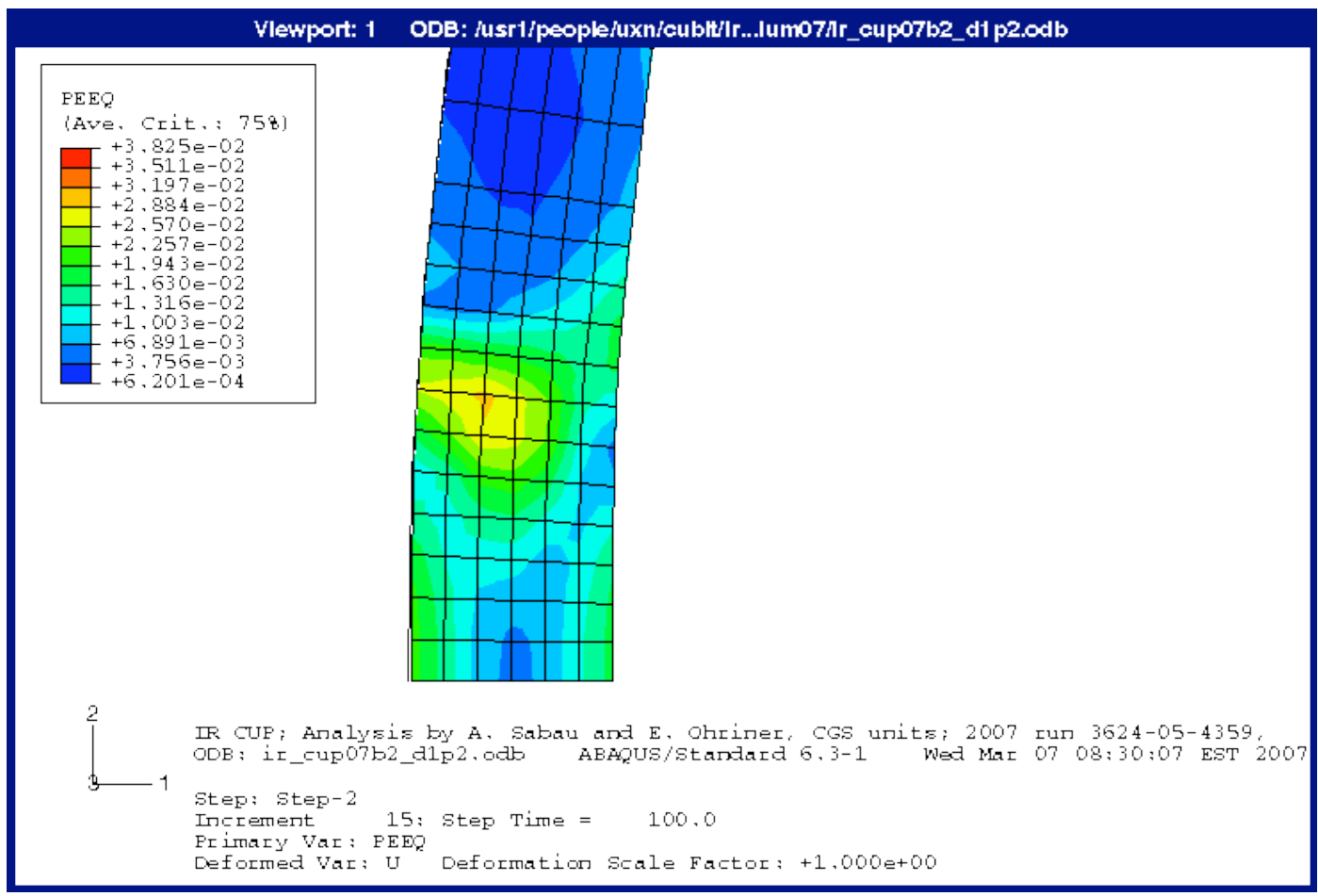

(b)

Figure 11. Calculated equivalent plastic strain for cup 4359 for case a) $0.03 \mathrm{~mm}$ radial die clearance at $55 \mathrm{kN}$ load and b) $0.03 \mathrm{~mm}$ radial die clearance at $90 \mathrm{kN}$ load. The figure shows the region corresponding to half of the cup cross-section with the centerline of the original depression at the lower left of the section. 


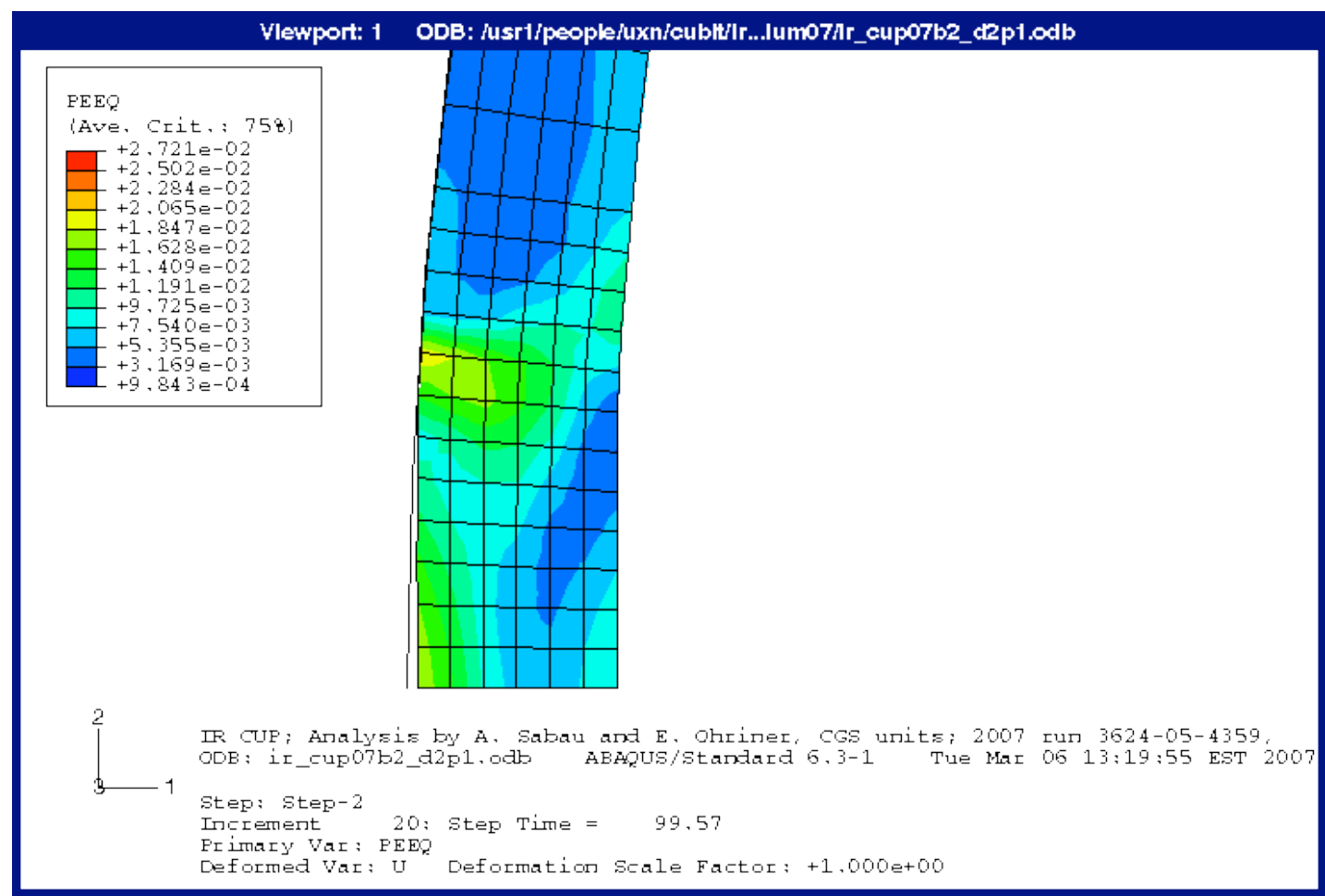

(c)

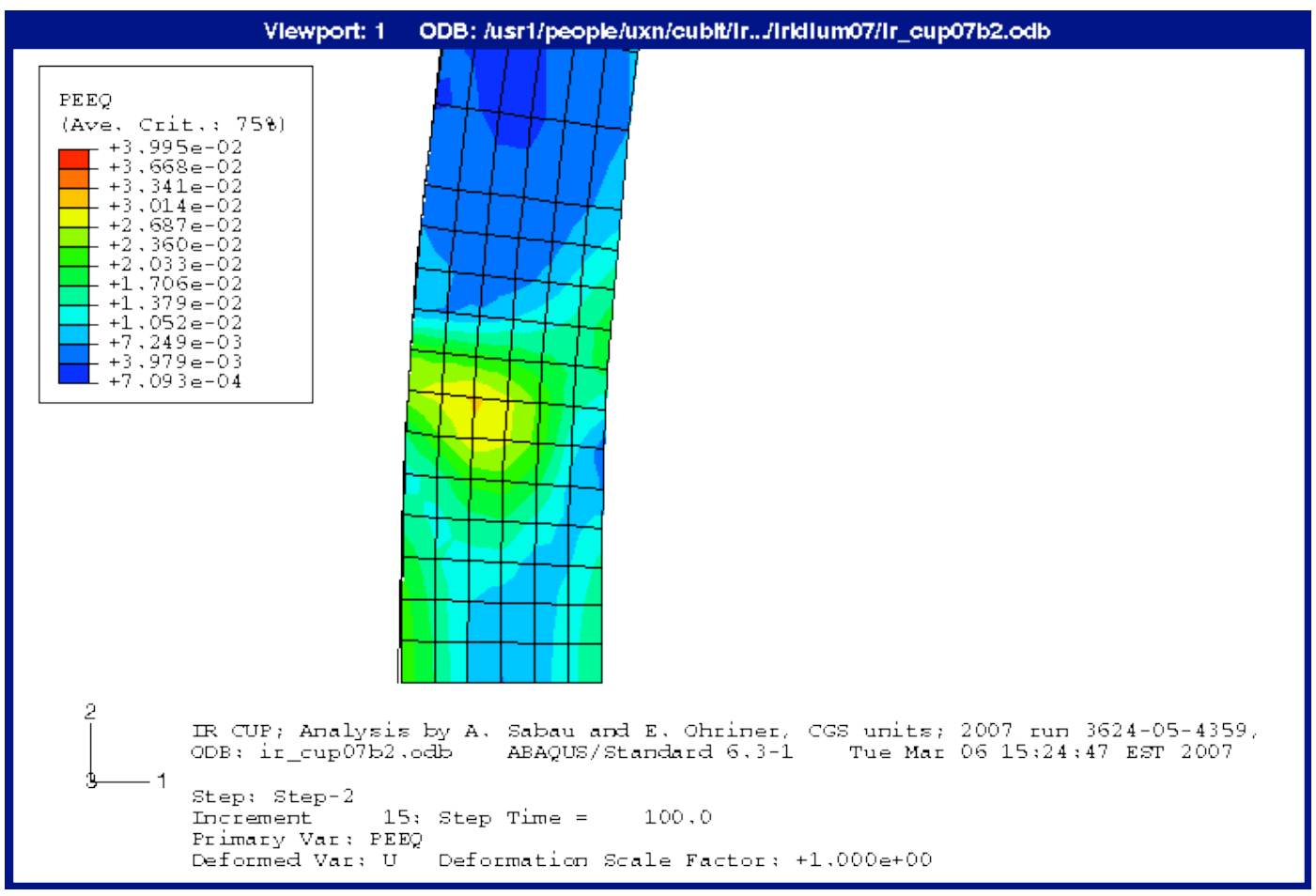

(d)

Figure 11 (continued). Calculated equivalent plastic strain for cup 4359 for case c) $0.05 \mathrm{~mm}$ radial die clearance at $55 \mathrm{kN}$ load and d) $0.05 \mathrm{~mm}$ radial die clearance at 90 $\mathrm{kN}$ load. 


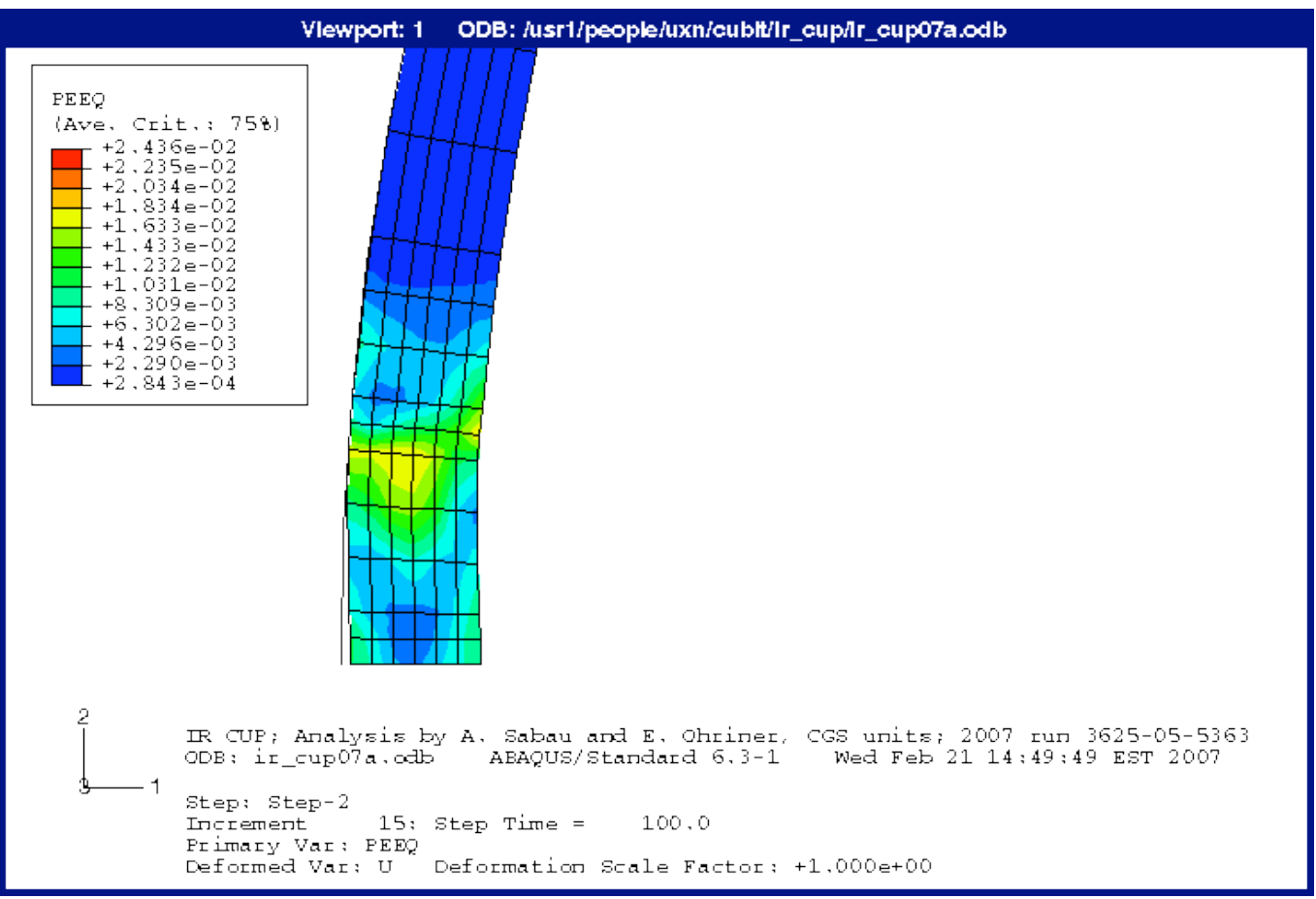

(a)

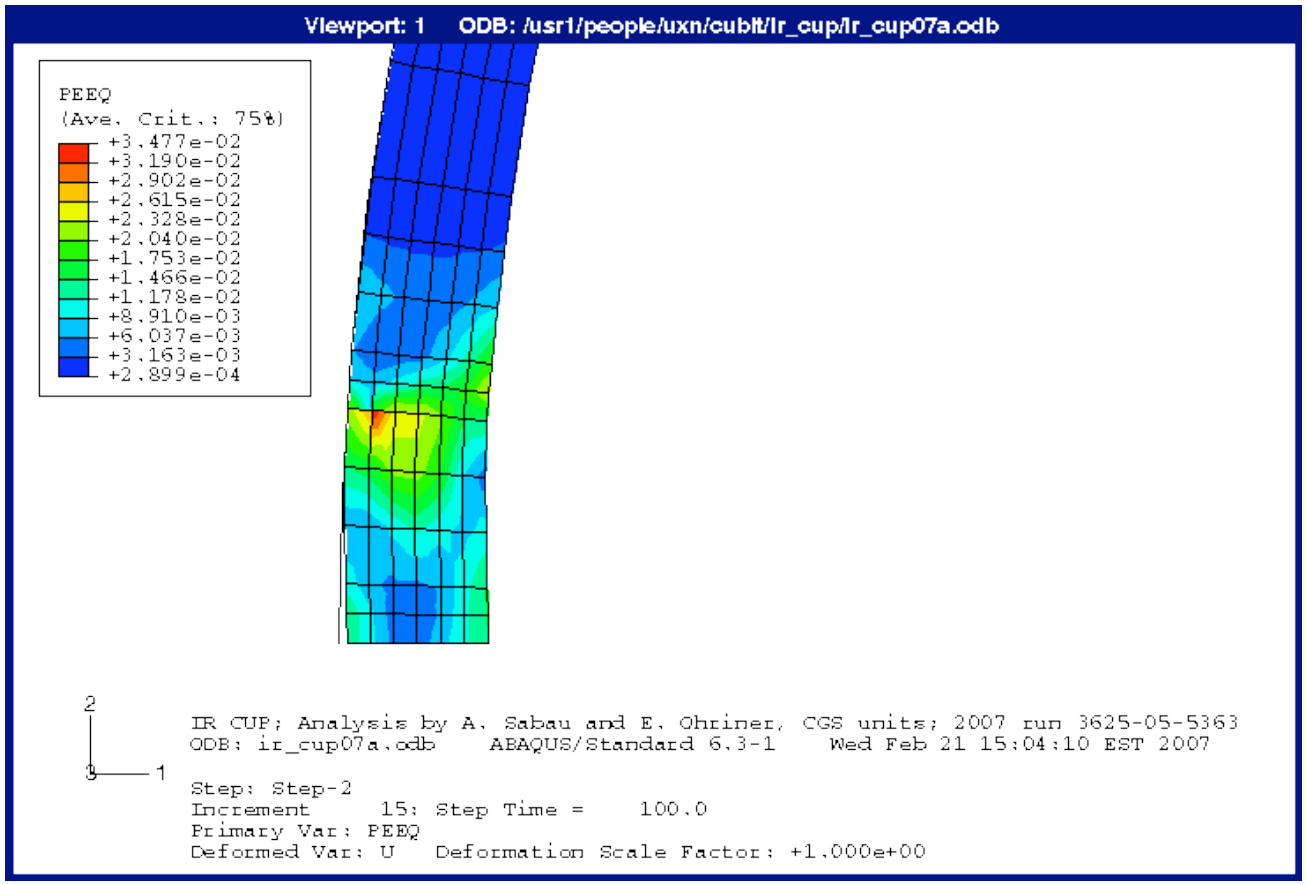

(b)

Figure 12. Calculated equivalent plastic strain for cup 5363 with $0.05 \mathrm{~mm}$ radial die clearance for case a) $55 \mathrm{kN}$ load and b) $90 \mathrm{kN}$ load. 
Table 2. Calculated Maximum Equivalent Plastic Strain and Depression Depth for Sized Cups

\begin{tabular}{|c|c|c|c|c|c|}
\hline $\begin{array}{c}\text { Sized } \\
\text { Cup } \\
\text { Identity }\end{array}$ & $\begin{array}{c}\text { Applied } \\
\text { Load, } \mathbf{k N}\end{array}$ & $\begin{array}{c}\text { Initial Die } \\
\text { Clearance mm }\end{array}$ & $\begin{array}{c}\text { Maximum } \\
\text { Equivalent Plastic } \\
\text { Strain \% }\end{array}$ & $\begin{array}{c}\text { Change in Depression } \\
\text { Depth mm }\end{array}$ & $\begin{array}{c}\text { Final Depression } \\
\text { Depth mm }\end{array}$ \\
\hline & & & & & 0.023 \\
\hline 4359 & 55 & 0.03 & 2.0 & 0.038 & 0.027 \\
\hline & 90 & 0.03 & 3.0 & 0.022 & 0.028 \\
\hline & 55 & 0.05 & 2.0 & 0.038 & 0.012 \\
\hline & 90 & 0.05 & 3.1 & & 0.039 \\
\hline & & & & 0.031 & 0.022 \\
\hline 5363 & 55 & 0.05 & 2.3 & 0.048 & \\
\hline & 90 & 0.05 & 3.1 & & \\
\hline
\end{tabular}

The depth of the depression following sizing was calculated using displacement values obtained as output from each sizing simulation. The value of the displacement at a location on the cup at 90 degrees from the depression was used as the net change in overall nominal cup radius. This value was subtracted from the displacement at the centerline of the depression to obtain the movement of material with respect to the cup wall. This difference was then subtracted from the original depression depth to calculate the final depth. The calculated final depression depths are listed in Table 2.

The measured final depression depth for cup 4359 of $0.028 \mathrm{~mm}$ (Table 1) is close to the calculated values of $0.027 \mathrm{~mm}$ or $0.028 \mathrm{~mm}$ for an applied sizing load of $55 \mathrm{kN}$. The measured final depression depth for cup 5363 of $0.035 \mathrm{~mm}$ (Table 1) also is close to the calculated value of $0.039 \mathrm{~mm}$ for an applied sizing load of $55 \mathrm{kN}$.

The results of the three-point bend simulation are summarized in Table 3. The strain values obtained from a simple bend formula are in good agreement with the calculated values of the maximum equivalent plastic strain for each of the three bend radii. The equivalent plastic strain for the bend sample with a radius of $12.7 \mathrm{~mm}$ and a nominal maximum strain of $2.5 \%$ is shown in Figure 12.

Table 3. Maximum Strain Values Calculated for 90 Degree Bend Samples

\begin{tabular}{cccc}
\hline $\begin{array}{c}\text { Mandrel } \\
\text { radius } \\
\text { mm }\end{array}$ & $\begin{array}{c}\text { Formula } \\
\text { engineering } \\
\text { fiber strain }\end{array}$ & $\begin{array}{c}\text { Formula } \\
\text { true } \\
\text { fiber strain }\end{array}$ & $\begin{array}{c}\text { ABAQUS } \\
\text { equivalent } \\
\text { plastic strain }\end{array}$ \\
\hline & & & \\
25.4 & 0.013 & 0.013 & 0.014 \\
12.7 & 0.026 & 0.025 & 0.027 \\
6.4 & 0.05 & 0.049 & 0.053 \\
\hline
\end{tabular}




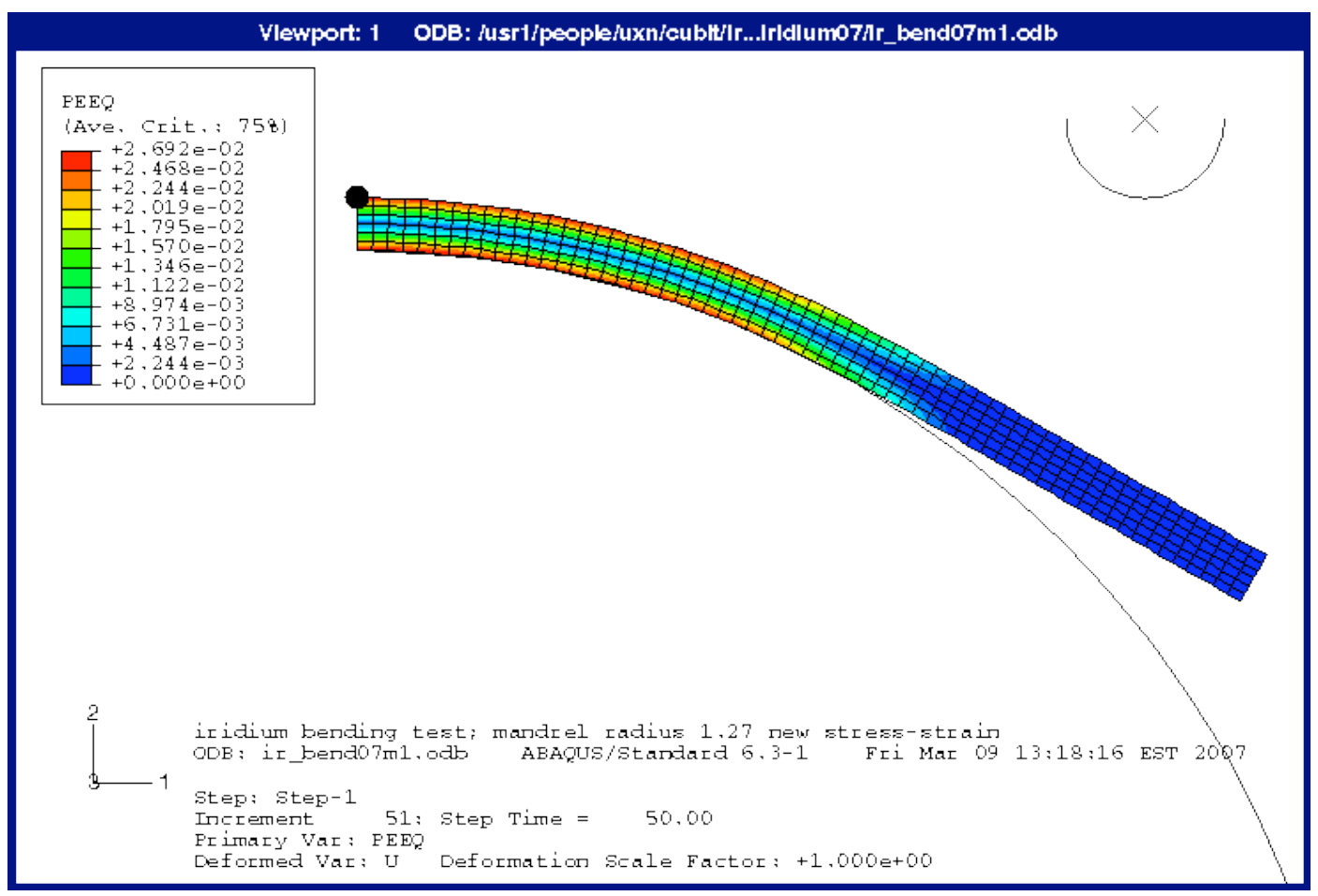

Figure 13. Calculated equivalent plastic strain for simulation of $0.67-\mathrm{mm}$ thick sheet bent 90 degrees over a rigid cylindrical bar of $12.7 \mathrm{~mm}$ radius.

\section{DISCUSSION}

The iridium alloy cup sizing operation has the potential to introduce low levels of plastic strain into the cups. The formed cups are sized after recrystallization and impressions in the formed cups may be subjected to plastic deformation during the sizing operation. A previous investigation [1] evaluated grain growth in bend samples subjected to a "worst-case" thermal exposure. This thermal cycle consisted of the standard fabrication exposures followed by one month at $950 \mathrm{C}$, plus three months at $1330 \mathrm{C}$, plus 3 minutes at $1580 \mathrm{C}$. Under these conditions there was minimal evidence of abnormal grain growth for material with $2.5 \%$ strain in bending. In the case of $5.0 \%$ strain in bending, a region of abnormal grain growth extended about one quarter of the material thickness from both the inner and outer surfaces. No strain levels between $2.5 \%$ and $5.0 \%$ were studied.

The potential for abnormal grain growth during a "worst-case" thermal exposure can be evaluated for individual formed cups by using a finite element simulation to determine the maximum equivalent plastic strain introduced during the sizing operation. A value of $2.5 \%$ plastic strain or less indicates that cup should exhibit normal grain growth in a "worst-case" scenario. There is good evidence that neither of the two cups evaluated in this study have a local plastic strain value in excess of $2.5 \%$. The calculated maximum 
plastic strains for cups 4359 and 5363 are $2.0 \%$ and $2.3 \%$, respectively, at the nominal sizing load of $55 \mathrm{kN}$. The change in the depression depth and the final depression depth are in good agreement for the $55 \mathrm{kN}$ sizing load. It is expected, therefore, that these two cups would exhibit normal grain growth and perform normally under all potential conditions of use.

The study also included simulations to evaluate the sensitivity of plastic strain from the sizing operation to process variables of sizing load and sizing die clearance. The plastic strain is sensitive to the sizing load. Although the simulations were limited to two values of load, the results suggest that the maximum plastic strain is roughly proportional to sizing load. The sizing load should be well controlled in order to minimize uncertainties in the plastic strain for cups that have some depressions or wrinkles in the wall surface. The load must be sufficient to obtain cups of acceptable roundness, but not so high as to unnecessarily introduce excess plastic strain in these cups. The maximum plastic strain is not sensitive to the sizing die clearance within the normal range of clearance values.

In general the maximum plastic strain can be expected to be sensitive to local geometry and local changes in geometry during sizing. While normal changes in die clearance can have significant effects on local displacement of the cup, the strains involved are small since the strain is distributed over the entire cup. In contrast, the effect of sizing on a depression is to cause displacements in which strains are concentrated locally. The magnitude of the strain can be expected to increase with the initial depression depth, but it is also affected by the width of the depression.

\section{CONCLUSIONS}

The conclusions of this study of plastic strain resulting from the sizing of DOP-26 iridium-alloy cups are as follows:

1. The ABAQUS ${ }^{\mathrm{TM}}$ finite element software is capable of modeling the deformation and resulting plastic strains caused by sizing operations on cups which have impressions in the cup walls due to irregularities from the deep drawing operations.

2. The calculated maximum plastic strain levels for the two sized cups in this study were below $2.5 \%$, a value shown to be below the critical strain for abnormal grain growth during a simulated service exposure.

3. After sizing, the region of maximum plastic strain is located about $6^{\circ}$ away from the centerline of the original depression, near the edge of the depressed region.

4. The calculated maximum plastic strain was found to increase with increased applied sizing load. 
5. The calculated maximum plastic strain was found to be insensitive to the clearance between cup and sizing die.

\section{REFERENCES}

1. C. G. McKamey, E. H. Lee, G. B. Ulrich, J. L. Wright, and E. P. George, Grain Growth Behavior of DOP-26 Iridium Clad Vent Set Cup Used in Radioisotope Thermoelectric Generators, ORNL/TM-2002/15 (2002).

2. G. Riontino, C. Antonione, L. Batteszzati, F. Marion, and M. C. Tabasso, J. Mat. Sci. 14, 86-90 (1979).

3. J. B., Koo, D. Y. Yoon, M. F. Henry, Met and Mat Trans. A 33, (12) 3803-3815 (Dec 2002).

4. J. H. Schneibel, C. A. Carmichael, and E. P. George, High Strain Rate Tensile Testing of DOP-26 Iridium, ORNL/TM-2007/81 (2007).

5. Jürgen Merker and David Lupton, Platinum Metals Rev., 45, (2) 74-82 (2001). 


\section{INTERNAL DISTRIBTUION}

1. E. P. George

2-4. J. F. King

5. R. G. Miller

6-8. E. K. Ohriner
9. A. S. Sabau

10-12. G. B. Ulrich

13-14. ORNL Laboratory Records-OSTI

15. ORNL Laboratory Records-RC

\section{EXTERNAL DISTRIBUTION}

16. Robert T. Carpenter, Orbital Sciences Corporation 20030 Century Blvd., Suite 102, Germantown, MD 20874

17. John Dowicki, Office of Radioisotope Power Systems, NE-34/GTN, U. S. Department of Energy, 1000 Independence Avenue SW, Washington, DC 20585-1290

18. Stephen G. Johnson, Idaho National Laboratory, P. O. Box 1622, MS-6122, Idaho Falls, ID 83415

19. Emil Skrabek, Orbital Sciences Corporation, 2003 Century Blvd., Suite 102, Germantown, MD 20874

20. Craig E. Van Pelt, Los Alamos National Laboratory, P. O. Box 1633, Los Alamos, NM 87545

21. Office of Assistant Manager for Energy Research and Development, U.S. Department of Energy Oak Ridge Operations, P.O. Box 2001, Oak Ridge, TN 37831-8600 